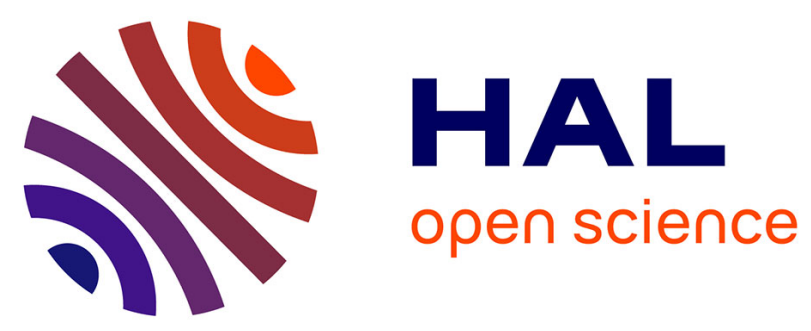

\title{
Definition and experimental determination of a soil-water retention surface
}

\author{
Simon Salager, Moulay Saïd El Youssoufi, Christian Saix
}

\section{To cite this version:}

Simon Salager, Moulay Saïd El Youssoufi, Christian Saix. Definition and experimental determination of a soil-water retention surface. Canadian Geotechnical Journal, 2010, 47, pp.609-622. 10.1139/T09123. hal-00844362

\author{
HAL Id: hal-00844362 \\ https://hal.science/hal-00844362
}

Submitted on 15 Jul 2013

HAL is a multi-disciplinary open access archive for the deposit and dissemination of scientific research documents, whether they are published or not. The documents may come from teaching and research institutions in France or abroad, or from public or private research centers.
L'archive ouverte pluridisciplinaire HAL, est destinée au dépôt et à la diffusion de documents scientifiques de niveau recherche, publiés ou non, émanant des établissements d'enseignement et de recherche français ou étrangers, des laboratoires publics ou privés. 


\title{
Definition and experimental determination of a soil-water retention surface
}

\author{
S. Salager, M.S. El Youssoufi, and C. Saix
}

\begin{abstract}
This paper deals with the definition and determination methods of the soil-water retention surface (SWRS), which is the tool used to present the hydromechanical behaviour of soils to highlight both the effect of suction on the change in water and total volumes and the effect of deformation with respect to the water retention capability. An experimental method is introduced to determine the SWRS and applied to a clayey silty sand. The determination of this surface is based on the measurement of void ratio, suction, and water content along the main drying paths. These paths are established for five different initial states. The experimental results allow us to define the parametric equations of the main drying paths, expressing both water content and void ratio as functions of suction and initial void ratio. A model of the SWRS for clayey silty sand is established in the space (void ratio - suction - water content). This surface covers all possible states of the soil inside the investigated range for the three variables. Finally, the SWRS is used to study the relations between water content and suction at a constant void ratio and between void ratio and suction at a constant water content.

Key words: water retention, hydromechanical coupling, retention behaviour.

Résumé : Cet article traite de la définition et des méthodes de détermination de la surface de rétention sol-eau («SWRS ») comme outil de représentation du comportement hydromécanique de sols permettant de mettre en évidence à la fois l'effet de la succion sur les changements de volumes (volume d'eau et volume total) et l'effet de la déformation sur la capacité de rétention d'eau des sols. Une méthode expérimentale de détermination de la SWRS du sol est présentée en détails puis appliquée pour un sable limoneux argileux. La prise en compte de la déformation conduit à une représentation surfacique à partir de la mesure de triplets (indice des vides - succion - teneur en eau) le long des chemins de séchage principaux. Ces chemins sont établis pour cinq états initiaux différents. Les résultats expérimentaux permettent d'établir les équations paramétriques des chemins de séchage principaux exprimant l'indice des vides et la teneur en eau en fonction de la succion et de l'indice des vides initial. Un modèle de surface caractéristique sol-eau est élaboré pour le sable limoneux argileux dans l'espace (indice des vides - succion - teneur en eau). Cette surface couvre tous les états possibles du sol dan les gammes étudiées des trois variables. La SWRS est finalement utilisée pour Õtudier les relations entre la teneur en eau et la succion pour un indice des vides constant, et entre l'indice des vides et la succion pour une teneur en eau constante.
\end{abstract}

Mots-clés : rétention d'eau, couplages hydromécanique, comportement hydrique.

\section{Introduction}

The retention behaviour of unsaturated soils is generally presented using the water retention curve. This fundamental curve links the variations of the potential energy of the liquid phase, usually characterized by the suction, $s$, to the variations of the saturation state, characterized by the water content, $w$, or the degree of saturation, $S_{\mathrm{r}}$. The retention curve has been widely studied during the past several decades with a focus on the $(i)$ fitting equation (Brooks and Corey 1964; Fredlund and Xing 1994), (ii) influence of soil compaction conditions (Vanapalli et al. 1999; Sugii et al.

Received 19 February 2009. Accepted 14 October 2009.

Published on the NRC Research Press Web site at cgj.nrc.ca on 21 May 2010.

S. Salager. ${ }^{1}$ Laboratoire de Mécanique des Sols, École

Polytechnique Fédérale de Lausanne, Station 18, 1015 Lausanne, Switzerland.

M.S. EI Youssoufi and C. Saix. Laboratoire de Mécanique et Génie Civil, Université Montpellier 2, Place Eugène Bataillon, CC048, 34095 Montpellier CEDEX 5, France.

${ }^{1}$ Corresponding author (e-mail: simon.salager@epfl.ch).
2002; Verbrugge and Fleureau 2002), (iii) modelling of hysteresis (Li 2005; Pham et al. 2005; Nuth and Laloui 2008), and (iv) influence of temperature (Romero et al. 2001; Imbert et al. 2005; Tang 2005; Salager et al. 2006).

The retention behaviour as defined above is unable to account for the phenomena that induces hydromechanical couplings. It is obvious, however, that the water retention curve depends on the soil density (Miller et al. 2002; Sugii et al. 2002; Tarantino and Tombolato 2005) and that soil deformation is responsible for suction variations. Therefore, for the construction of a retention constitutive law, it is essential to consider the evolution of the density state in the course of drying or wetting processes (Delage et al. 1998; Romero 1999; Fleureau et al. 2002; Olchitsky 2002). In addition, the tool used to present the hydromechanical behaviour of soils has to highlight both the suction effect on the volume change (water and total volumes) and the deformation effect on the water retention capability. This tool has to be defined by a function that expresses the potential energy of the liquid phase with respect to the variations of the water volume and the total volume. The variables chosen in this study are suction $(s)$, water content $(w)$, and void ratio $(e)$ because they are usually used in soil science and are easily measura- 
ble. The function that links these three variables is presented as a surface called the "soil-water retention surface" (SWRS). It contains and generalizes the concept of the water retention curve in the case where the deformations can not be neglected.

Some results are available in the field of hydromechanical characterization, but they usually provide partial and simplified representations through the water retention curve. The aim of the investigation presented in this paper is to define a more general concept of the SWRS and propose a representation of it from a broad set of experimental data.

In the next section, basic elements of hydromechanical couplings are presented from both theoretical and experimental backgrounds. This helps to highlight the necessity of a tool that is more general than the water retention curve to characterize the retention behaviour of soils. Then, an experimental method to determine the SWRS is introduced and applied to a clayey silty sand. The determination of this surface is based on the measurement of the triplets $(e, s, w)$ along the main drying paths. These paths are established for five different initial states characterized by their void ratio and water content at saturation. The experimental results allow us to define the parametric equations of the main drying paths expressing both water content and void ratio as two functions of suction and initial void ratio. A model of the SWRS for clayey silty sand is established in the space ( $e-$ $s-w)$. This surface covers all possible states of the soil for the drying paths inside the investigated range for the three variables. Finally, using an analytical framework based on the differential of the suction with regard to water content and void ratio, the SWRS is used to study the relations between water content and suction at a constant void ratio and between void ratio and suction at a constant water content.

\section{Basic elements of hydromechanical couplings}

\section{Theoretical aspects}

In the particular case of a saturated soil, the void ratio is simply related to the water content by $e=G_{\mathrm{s}} w$, where $G_{\mathrm{s}}$ is the specific weight of the soil. In the general case of unsaturated soils, we have $S_{\mathrm{r}} e=G_{\mathrm{s}} w$ so that void ratio and water content are independent quantities.

In this context, many authors - notably Biot (1972), Fredlund and Morgenstern (1976), and Coussy (1995) have shown that in the general hydromechanical framework, the void ratio and water content have to be defined independently by a function with two variables: one characterizing the potential energy variations of water and the other characterizing the stress state variations. This can be written as

[1] $\quad w=w\left(s, \sigma_{\text {net }}\right)$

[2] $e=e\left(s, \sigma_{\text {net }}\right)$

where $\sigma_{\text {net }}$ is the net stress tensor.

To focus on the retention behaviour, one may consider the case of nonlinear poroelasticity. In this framework, Devillers et al. (2008) expressed the suction as a function of void ratio and water content as follows:
[3] $\mathrm{d} s=\left(M_{\mathrm{ww}}-\frac{p_{\mathrm{g} 0}}{n_{\mathrm{g} 0}}\right)\left(b_{\mathrm{w}} \frac{\mathrm{d} e}{1+e_{0}}-\frac{\rho_{\mathrm{s}}}{\rho_{\mathrm{w} 0}} \frac{\mathrm{d} w}{1+e_{0}}\right)$

where $M_{\mathrm{ww}}$ is Biot's modulus; $p_{\mathrm{g}}$ and $n_{\mathrm{g}}$ are the pressure and volume fraction of the gas phase, respectively; $b_{\mathrm{w}}$ is Biot's coefficient; $\rho_{\mathrm{s}}$ and $\rho_{\mathrm{w}}$ are the specific density of the solid and liquid phases, respectively; and the subscript 0 refers to the initial state. In the same way, Fredlund (1979) and later Saix (1991) defined a hydromechanical framework from experimental data to analyze the retention behaviour of soils, which could be expressed as

[4] $\Delta w=-K_{\mathrm{M}} \Delta e-K_{\mathrm{H}} \log \frac{s_{\mathrm{f}}}{s_{\mathrm{i}}}$

where $K_{\mathrm{M}}$ is a coefficient related to the coupling between water content and void ratio variations; $K_{\mathrm{H}}$ is a coefficient related to the coupling between water content and suction variations; and $s_{\mathrm{f}}$ and $s_{\mathrm{i}}$ are the final and initial values of suction, respectively.

Equations [3] and [4] emphasize the fact that two variables are necessary to define the retention state of an unsaturated soil. Therefore, the retention behaviour of a soil has to be represented by a surface instead of the usual water retention curve.

\section{Experimental aspects}

Most experimental studies hint at the influence of density on the water retention curve of soils (Vanapalli et al. 1999; Watabe et al. 2000; Fleureau et al. 2002; Miller et al. 2002; Sun et al. 2007). They provide compelling evidence for the fact that the definition of the retention behaviour of a soil implies either water content versus suction or degree of saturation versus suction, as well as a variable characterizing the total volume change. To analyze in detail the effect of density on the retention behaviour, one may consider the parameters of the functions used to fit water retention curves. Several functional forms already exist (Gardner 1958; Brooks and Corey 1964; Van Genuchten 1980; Fredlund and Xing 1994; Kosugi 1994), but their parameters are always linked, in a more or less direct way, to three characteristics: the air-entry value, $s_{\mathrm{a}}$; the slope of the high desaturation linear part $\varphi$; and the residual water content, $w_{\mathrm{r}}$.

Several studies (Kawaï et al. 2000; Romero and Vaunat 2000; Karube and Kawaï 2001; Zhou and Yu 2004) suggest that the parameter of the water retention curve most influenced by the initial density is the air-entry value. A suction loading applied to an unsaturated soil induces a partial migration of the liquid phase. From the air-entry value, the drainage process becomes faster. This transition in retention behaviour reflects a limit level of the capillary tension for the soil. This limit varies in the reverse direction with respect to the pore size and hence, the void ratio. For this reason, it can be confirmed that the air-entry value declines as void ratio increases (Karube and Kawaï 2001). Kawaï et al. (2000) modeled the evolution of this parameter by a power law

[5] $s_{\mathrm{a}}=A e_{0}^{-B}$

where $e_{0}$ is the initial void ratio and $A$ and $B$ are the model parameters. The experimental works of Romero and Vaunat 
(2000) and Karube and Kawaï (2001) corroborate this model.

The reported results concerning the evolution of the slope $\varphi$ with respect to the density are not unanimous. This parameter is considered to be constant with respect to the initial void ratio for Romero and Vaunat (2000), decreases slightly with density increase for Miller et al. (2002) or is linked to the air-entry value by relation $\varphi=0.5+0.05 s_{\mathrm{a}}$ for Karube and Kawaï (2001) in the case of slightly plastic clay.

The residual water content or residual degree of saturation represent a transition to a state where the liquid phase is no longer continuous in the medium. Al-Mukhtar et al. (1999) determined the water retention curves for two series of samples prepared with a smectite, compacted at 1 and $10 \mathrm{MPa}$. They noted that, below a certain level of relative humidity $(98 \%)$, the water retention curves are similar. The ends of the curves, and thus the continuity limit of the liquid phase, are not influenced by the density. Likewise, Romero and Vaunat (2000) and Karube and Kawaï (2001) consider that, to a first approximation, this parameter is constant irrespective of initial conditions. Romero and Vaunat (2000) delimited two zones on the water retention curve of a double structure clayey medium: one corresponds to the interaggregate porosity and the other to the intraaggregate porosity. In the first one, corresponding to low suctions, the effect of hydromechanical couplings is very important; whereas, in the second one, corresponding to high suctions, the water retention curve is independent of the mechanical parameters such as void ratio. This point is supported by the experimental data of Vanapalli et al. (1999), which suggested that for a clayey sand the water retention curve is independent of the mechanical history in the range of high suctions.

\section{Experimental programme}

The experimental programme was established to target the following goals:

- Show experimentally the relevance of the SWRS concept.

- Illustrate a complete construction method of this surface for a soil (the clayey silty sand). This requires the parametric equations of the main drying path of this soil. To extend the domain of validity, the model will have to rely on experimental data covering a broad range of void ratios.

A clayey silty sand was used in this testing program. This soil is classified as SC-CL according to the Unified Soil Classification System (ASTM 2006). The liquid and plastic limits are $25 \%$ and $14.5 \%$, respectively; and the sand, silts, and clay fractions are $72 \%, 18 \%$, and $10 \%$, respectively. The clay fraction consists mainly of smectite, chlorite, and phyllite. The optimum water content is $14.5 \%$ at a dry density $\rho_{\mathrm{d}}=1.86$ and the specific gravity of the soil is $G_{\mathrm{s}}=$ 2.65. The soil was air-dried for several days and passed through a $2 \mathrm{~mm}$ sieve. The soil, well-mixed with the necessary water quantity, was placed in airtight boxes for at least $48 \mathrm{~h}$ to homogenize the water repartition. Each sample was compacted statically in a single layer $(30 \mathrm{~mm}$ diameter and $10 \mathrm{~mm}$ high) within a mould to obtain the required water content and dry density conditions of fabrication (moulding state). The experimental program involved five series of samples with each series compacted to a different density
(Table 1). For the loosest state, the samples were compacted to a dry density $\rho_{\mathrm{d}}=1.35$, corresponding to a void ratio of 0.96 . To differentiate well between the densities and ensure the continuity of the curves at the same time, the dry densities of distinct samples differed by 0.15 . The samples of the most compacted series had a dry density of 1.95 . The moulding water content was equal to $18 \%$ for the three series of lower densities, which corresponds to the wet side of the Proctor compaction curve. For the others, this water content is too high for a a good compaction. For these series, the compaction was carried out at lower water contents of $14 \%$ and $12 \%$. These values of the water content were selected to keep the moulding state close to the Proctor optimum conditions.

To obtain the initial state, the samples were saturated by imbibition for $2 \mathrm{~h}$ on a ceramic plate linked to a pure water tank. The measured characteristics at the end of this process thus define the initial states of samples. Figure 1 displays the moulding and initial states of each series compared with the saturation line and Proctor compaction curve. The moulding and initial sample characteristics of the five series are summarized in Table 1.

The suction loading was applied to the samples in a pressure-plate apparatus (Salager 2007), using the axis translation technique or a sorption bench (Salager et al. 2008), by the vapor equilibrium method. For each series, an average of 16 to 18 suction values were imposed and the main drying paths determined. At equilibrium, the water content and void ratio of the samples were measured. Each measurement is an average over three samples and more than 240 samples were used. Hence, the number of available triplets $(s, w, e)$ is above 80 .

The adopted procedure for volume measurement is based on the general method using fluid displacement described, for instance, by Head (1980), with some modifications added by Péron et al. (2007). The fluid used for volume measurement in this method is Kerdane (oil from which aromatics are extracted). First, a clean and dry pycnometer is filled with Kerdane and weighed, constituting the mass $m_{\mathrm{P} 1}$. Afterwards, each sample set aside for volume measurement is weighed to determine its wet mass, $m_{1}$. The sample is then lowered into a bath of Kerdane. Kerdane is nonmiscible in water and invades the pore spaces filled with air without affecting the soil structure. After $3 \mathrm{~h}$, the sample is removed from the Kerdane bath. The estimated duration of the process (i.e., $3 \mathrm{~h}$ ) is based on our observations: at the beginning of the bath, air bubbles are released from the samples; after $3 \mathrm{~h}$, this phenomenon stops. The sample is then very carefully wiped with absorbent paper and weighed again to obtain $m_{2}$ (mass of the Kerdane-water saturated sample). Then this sample is placed into an empty pycnometer. The remaining volume of the pycnometer containing the saturated wet sample is then entirely filled with Kerdane, adopting the same filling technique as that used for the determination of $m_{\mathrm{P} 1}$, taking special care to avoid any air bubble entrapment. At this stage, it is assumed that the total volume of the sample has been measured: the preliminary Kerdane bath actually prevents Kerdane from penetrating into the sample pore space during pycnometer filling. This pycnometer is weighed, yielding the mass $m_{\mathrm{P} 2}$ (mass of the pycnometer containing Kerdane and Kerdane-water saturated sample). 
Table 1. Moulding and initial states for the five series of samples.

\begin{tabular}{|c|c|c|c|}
\hline Series & $e$ & $\rho_{\mathrm{d}}\left(\mathrm{kg} \cdot \mathrm{m}^{-3}\right)$ & $w$ \\
\hline \multicolumn{4}{|c|}{ Moulding state } \\
\hline 1 & 0.96 & 1350 & 0.18 \\
\hline 2 & 0.77 & 1500 & 0.18 \\
\hline 3 & 0.61 & 1650 & 0.18 \\
\hline 4 & 0.47 & 1800 & 0.14 \\
\hline 5 & 0.36 & 1950 & 0.12 \\
\hline \multicolumn{4}{|c|}{ Initial state } \\
\hline 1 & 1.01 & 1319 & 0.381 \\
\hline 2 & 0.86 & 1427 & 0.323 \\
\hline 3 & 0.68 & 1575 & 0.257 \\
\hline 4 & 0.55 & 1708 & 0.210 \\
\hline 5 & 0.44 & 1845 & 0.165 \\
\hline
\end{tabular}

Finally, the mass $m_{\mathrm{s}}$ (solid mass of the sample) is determined by oven drying. The sample volume, $V$, can be calculated using the following relationship:

[6] $\quad V=\frac{m_{\mathrm{P} 1}+m_{2}-m_{\mathrm{P} 2}}{\rho_{\mathrm{K}}}$

where $\rho_{\mathrm{K}}$ is the specific mass of Kerdane. The corresponding void ratio is determined using

[7] $e=\frac{V_{\mathrm{v}}}{V_{\mathrm{s}}}=\rho_{\mathrm{s}} \frac{m_{\mathrm{P} 1}+m_{2}-m_{\mathrm{P} 2}}{m_{\mathrm{s}} \rho_{\mathrm{K}}}$

where $V_{\mathrm{v}}$ and $V_{\mathrm{s}}$ are the volumes of void and solid particles, respectively; and $\rho_{\mathrm{s}}$ is the specific mass of the solid particles.

\section{Main drying path}

\section{Description}

The suction loading induces hydromechanical couplings in terms of water content and void ratio variations (Fleureau et al. 2002; Verbrugge and Fleureau 2002). For a complete description, the main drying paths must be presented in several projection planes or in the form of a tri-dimensional plot (Fig. 2; Biarez et al. 1988; Salager et al. 2007). Figure 2 shows an example obtained for series No. 2, where

- Plane $e=$ constant, for the water content versus suction plot (the suction axis is usualy plotted on a logarithmic scale), commonly called water retention curve.

- Plane $w=$ constant, for the void ratio versus suction plot, commonly called retention consolidation curve.

- Plane $s=$ constant, for the void ratio versus water content plot.

\section{Projection on the plane $e=$ constant}

Figure 3 shows the data points obtained for the five data sets in the projection plane $e=$ constant. These points allow us to build the water retention curves of the clayey silty sand compacted at different initial void ratios. In each case, for the low values of suction (below a few $\mathrm{kPa}$ ), the water content variations are low and for the intermediate suction values (between a few $\mathrm{kPa}$ and about $3000 \mathrm{kPa}$ ) these varia- tions are important and correspond to the high desaturation linear part.

For high values of suction, no significant hydromechanical coupling is observed, as the data converge to the same point for different sets. In fact, the influence of the initial void ratio is no longer visible beyond a suction in the range of 100-200 kPa. During mechanical loading, during static compaction in the fabrication of the sample for this study, the pore network of the soil is modified. The larger pores are easily crushed; whereas the smaller ones need higher stress to be reduced. However, the stress required to reduce the smallest pores may be high enough to break the grains (Fredlund and Pham 2007). In this way, the compaction has a strong effect on the low suctions part of the water retention curve while, for the high suctions, the water retention can be considered as unique (Delage and Graham 1995).

We use the function proposed by Fredlund and Xing (1994) to fit the water retention curves

$$
\text { [8] } w(s)=\left\{1-\frac{\ln \left[1+\left(s / s_{\mathrm{r}}\right)\right]}{\ln \left[1+\left(10^{6} / s_{\mathrm{r}}\right)\right]}\right\} \frac{w_{\text {sat }}}{\left\{\ln \left[\exp (1)+\left(s / s_{\mathrm{i}}\right)^{n}\right]\right\}^{m}}
$$

Four parameters need to be fixed points for this function: the slope of the linear part of high desaturation, $\varphi$; the intersection, $s_{\mathrm{p}}$, of this line with the $x$-axis; the residual suction, $s_{\mathrm{r}}$; and the suction at the inflexion point, $s_{\mathrm{i}}$. The values of $n$ and $m$ are determined from these four parameters (Salager 2007)

$$
\text { [9] } \quad m=3.67 \ln \left\langle\frac{w_{\text {sat }}\left\{1-\frac{\ln \left[1+\left(s_{\mathrm{i}} / s_{\mathrm{r}}\right)\right]}{\ln \left[1+\left(10^{6} / s_{\mathrm{r}}\right)\right]}\right\}}{\varphi \ln \left(s_{\mathrm{p}} / s_{\mathrm{i}}\right)}\right\rangle
$$

where $\varphi=w_{\mathrm{i}} /\left[\ln \left(s_{\mathrm{p}} / s_{\mathrm{i}}\right)\right]$

$$
\begin{aligned}
n=3.72 & \frac{1.31^{m+1}}{m}\left\{1-\frac{\ln \left[1+\left(s_{\mathrm{i}} / \mathrm{s}_{\mathrm{r}}\right)\right]}{\ln \left[1+\left(10^{6} / s_{\mathrm{r}}\right)\right]}\right\} \\
& \times\left\{\frac{\varphi}{w_{\text {sat }}}-\frac{s_{\mathrm{i}}}{1.31^{m}\left(s_{\mathrm{i}}+s_{\mathrm{r}}\right) \ln \left[1+\left(10^{6} / s_{\mathrm{r}}\right)\right]}\right\}
\end{aligned}
$$

Figure 3 shows the experimental points for different data sets. From these data the influence of the initial void ratio on the parameters of eq. [8] can be studied.

- $w_{\text {sat }}$ - The water content at saturation is directly linked to the initial void ratio by the following relation:

$$
\text { [11] } \quad w_{\mathrm{sat}}=\frac{e_{0}}{G_{\mathrm{s}}}
$$

where $G_{\mathrm{s}}$ is the specific density of the solid phase equal to 2.65 for the clayey silty sand.

- $\varphi, s_{\mathrm{r}}$, and $s_{\mathrm{p}}$ - One can note in Fig. 3 that the three parameters are independent from the initial void ratio. This stems from the fact that above a suction of about 100 $200 \mathrm{kPa}$, the data points of different sets coincide.

- $s_{\mathrm{i}}$ - Figure 3 shows that the inflexion suction decreases when the initial void ratio increases. The evolution of this parameter is correlated with the suction associated with the air-entry value $s_{\mathrm{a}}$. Miller et al. (2002) showed for four different soils that these two characteristics are proportional. Equation [5] was able to describe the evolution 
Fig. 1. Moulding and initial states of samples for the five series.

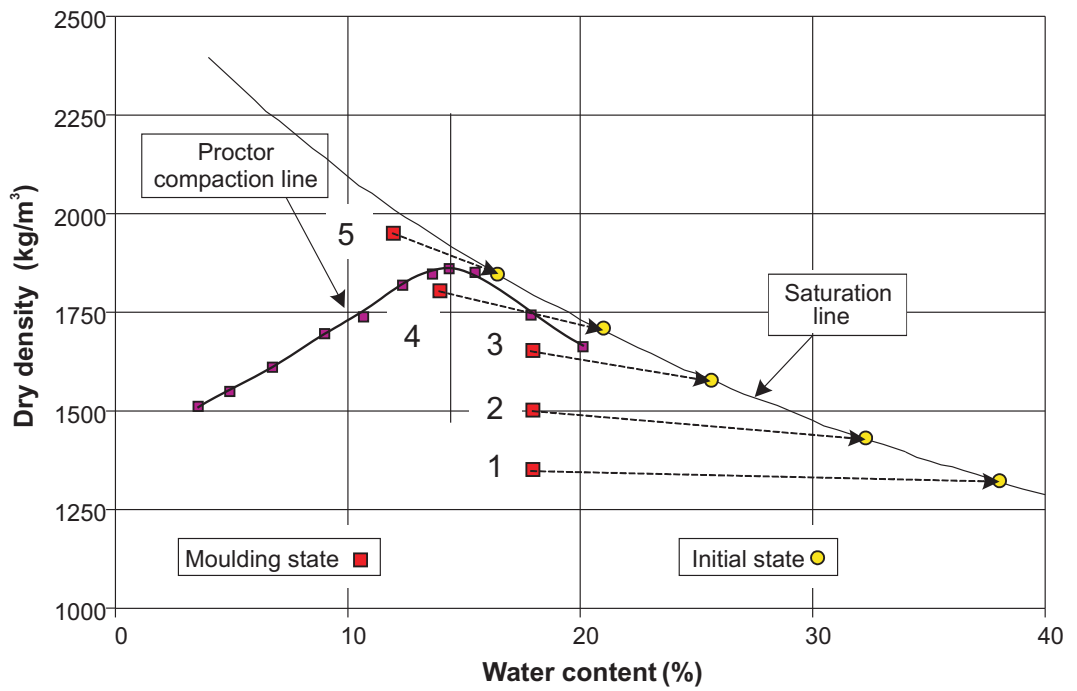

Fig. 2. Main drying path of series No. 2 plotted in the space $w-e-s$.

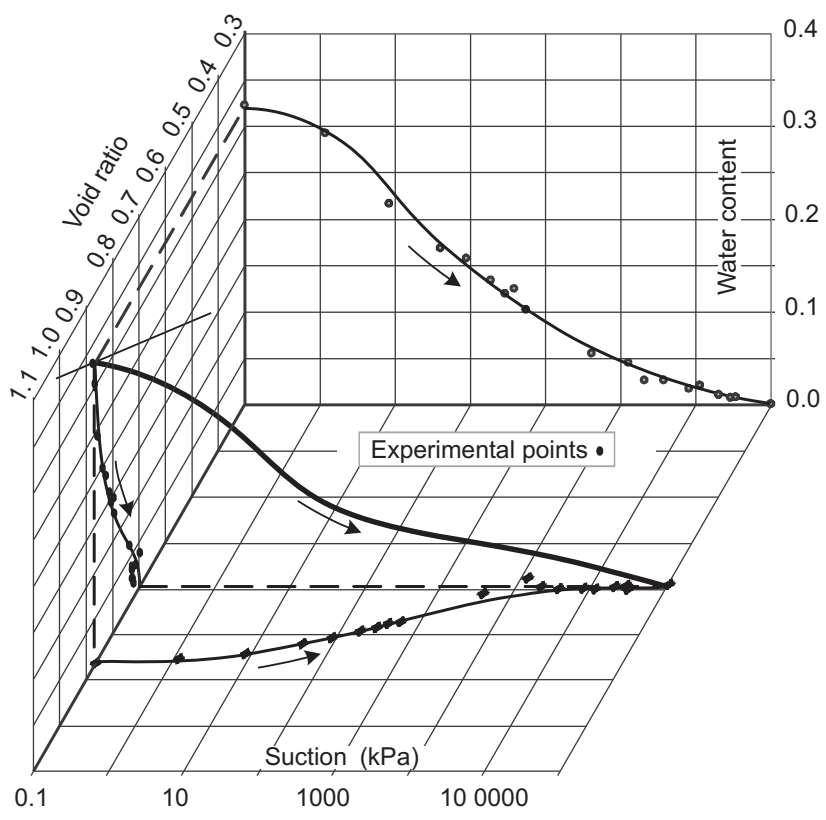

of $s_{\mathrm{a}}$ with respect to $e_{0}$ (Kawaï et al. 2000; Romero and Vaunat 2000; Karube and Kawaï 2001). It is used to model the evolution of $s_{\mathrm{i}}$ with respect to $e_{0}$. This equation can be written as

$$
\text { [12] } s_{\mathrm{i}}=A e_{0}^{-B}
$$

where $A$ and $B$ are model parameters depending on the soil. Their values are 2.29 and 6.72 , respectively, for the case of clayey silty sand. The Pearson product-moment correlation coefficient (PMCC) between experimental points and the fitting curve is 0.97 .

The values of the parameters $\varphi, s_{\mathrm{p}}, s_{\mathrm{r}}, w_{\text {sat }}$, and $s_{\mathrm{i}}$ for the best fits of the experimental data are given in Table 2. Fig- ure 4 displays the water retention curves obtained for different data sets. We observe a good agreement between the experimental data and the values predicted by the model.

\section{Projection in the plane $w=$ constant}

The plots of the void ratio as a function of the initial void ratio for different values of suction, shown in Fig. 5, indicate that these two terms are proportional. Similar results have been obtained by Ferber et al. (2008) for the case of free swelling tests performed on a clay and a silty clay. For a suction equal to zero, the proportionality coefficient is obviously equal to 1 (initial state of each test). Then, it decreases as the suction increases and saturates to a constant value of 0.79 beyond a suction of about $10000 \mathrm{kPa}$. This proportionality between void ratio and initial void ratio is true only in the case of the main drying paths.

As $\alpha$ is the proportionality coefficient, the equation relating the void ratio to the initial void ratio can be written as

[13] $\quad e\left(s, e_{0}\right)=\alpha(s) e_{0}$

Figure 6 shows the evolution of $\alpha$ with suction. The observed similarity between the shape of this curve and that of the water retention curve suggests that a fitting form similar to eq. [8] may work. This relation takes the following form:

$$
\begin{aligned}
\alpha 14] \quad \alpha(s)=0.79+\left\{1-\frac{\ln [1+(s / a)]}{\ln \left[1+\left(10^{6} / a\right)\right]}\right\} \\
\times \frac{b}{\left\{\ln \left[\exp (1)+(s / b)^{e}\right]\right\}^{d}}
\end{aligned}
$$

where the values of $a, b, d$, and $e$ are 1000, 0.21, 400, 2.896, and 0.466, respectively. Equations [13] and [14] make it possible to express the variations of the void ratio as a function of the suction and initial void ratio.

Figure 7 shows the plots of the fitting curves of the main drying path projected on the plane $w=$ constant for all data sets. We see that, on one hand, the model underestimates the effect of suction on the void ratio for the set corresponding 
Fig. 3. Experimental points and modelling parameter of the main drying path for the five data sets projected on the plane $e=$ constant.

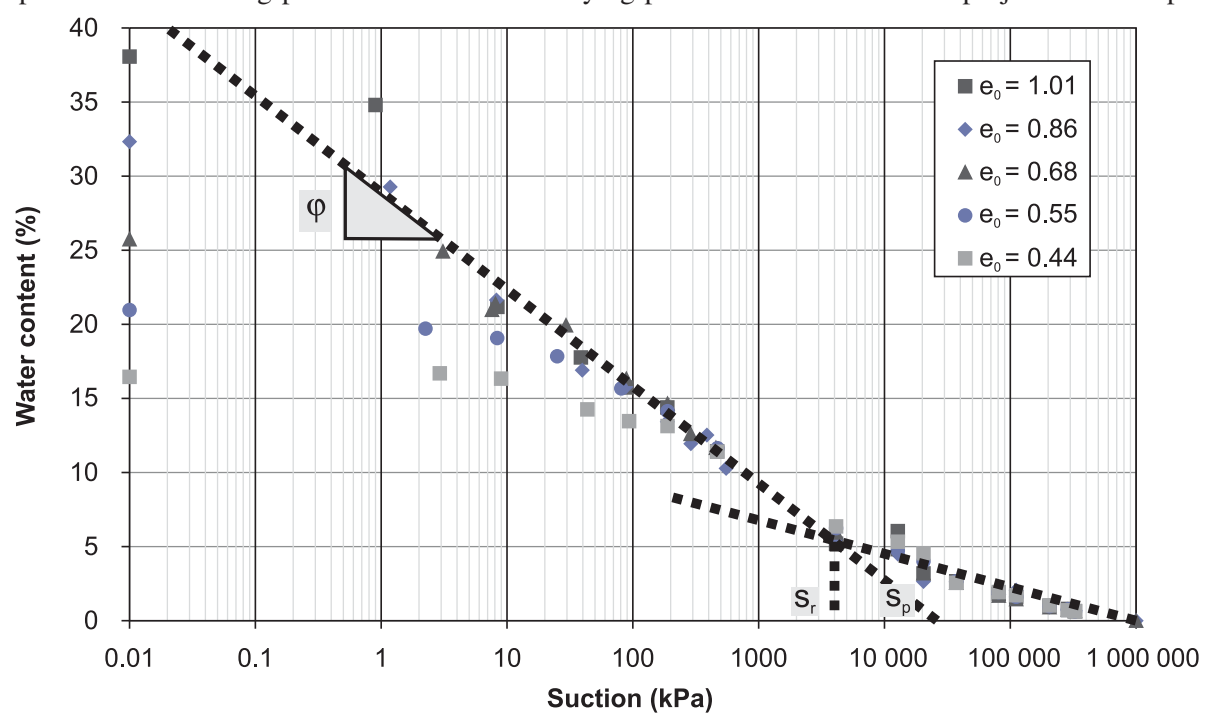

Table 2. Parameters of the fitting function $w\left(s, e_{0}\right)$ (eq. [8]).

\begin{tabular}{ll}
\hline Parameter & Value \\
\hline$\varphi$ & -0.03 \\
$s_{\mathrm{p}}(\mathrm{kPa})$ & 35000 \\
$s_{\mathrm{r}}(\mathrm{kPa})$ & 100 \\
$w_{\mathrm{sat}}$ & $e_{0} / 2.65$ \\
$s_{\mathrm{i}}(\mathrm{kPa})$ & $2.29 e_{0}^{(-6.72)}$ \\
\hline
\end{tabular}

to the highest initial void ratio and, on the other hand, it overestimates this effect for the set corresponding the lowest initial void ratios. These deviations result from the linear approximation between void ratio and initial void ratio. Nevertheless, the predictions of the model are reasonably good.

\section{Soil-water retention surface of the clayey silty sand}

Plotting the main drying paths of the clayey silty sand for a wide range of initial void ratios will generate the SWRS of this soil. A method to model this surface is proposed as follows.

From the parametric equations of the main drying paths determined previously, one can compute, for each value of the suction $s_{j}$, five couples $\left(w_{j}^{e_{0}}, e_{j}^{e_{0}}\right)$ corresponding to the five initial void ratios of different data sets. These points describe the evolution of water content with the void ratio at a given value of suction. Figure 8 displays the resulting curves.

The saturation line $\left(w_{\text {sat }}=e / G_{\mathrm{s}}\right)$ limits the accessible zone of the couples $(w, e)$. Under this line, for each suction $s=$
$1,10, \ldots, 1000000 \mathrm{kPa}$, the evolution of water content with void ratio can be represented by straight lines. The relation between water content and void ratio can therefore be written as

$$
\text { [15] } w=a e+b
$$

where the slope $a$ and the intersection $b$ depend on the suction.

The coordinates $w_{\text {int }}$ and $e_{\text {int }}$ of the intersection point between the saturation line and the line defined by eq. [15] are given by the relations

[16] $\quad w_{\text {int }}=a e_{\text {int }}+b$

and

[17] $\quad w_{\text {int }}=\frac{e_{\text {int }}}{G_{\mathrm{s}}}$

Hence,

[18] $\quad w_{\text {int }}=a w_{\text {int }} G_{\mathrm{s}}+b$

and

[19] $\quad b=w_{\text {int }}\left(1-a G_{\mathrm{s}}\right)$

Finally, eq. [15] can be written as

[20] $\quad w=a e+w_{\text {int }}\left(1-G_{\mathrm{s}} a\right)$

To establish the full expression of the water content, we need to take into account the fact that the couples $(w, e)$ are not permissible below the saturation line. In this way, the expression of the water content is defined by the following system of equations:

[21] $\quad w=\left\{\begin{array}{l}a e+w_{\text {int }}\left(1-G_{\mathrm{s}} a\right) \quad \text { for } a e+w_{\text {int }}\left(1-G_{\mathrm{s}} a\right)<\frac{e}{G_{\mathrm{s}}} \\ w_{\mathrm{sat}}=\frac{e}{G_{\mathrm{s}}} \quad \text { for } a e+w_{\text {int }}\left(1-G_{\mathrm{s}} a\right) \geq \frac{e}{G_{\mathrm{s}}}\end{array}\right.$ 
Fig. 4. Model and experimental results of the main drying path projected on the plane $e=$ constant.

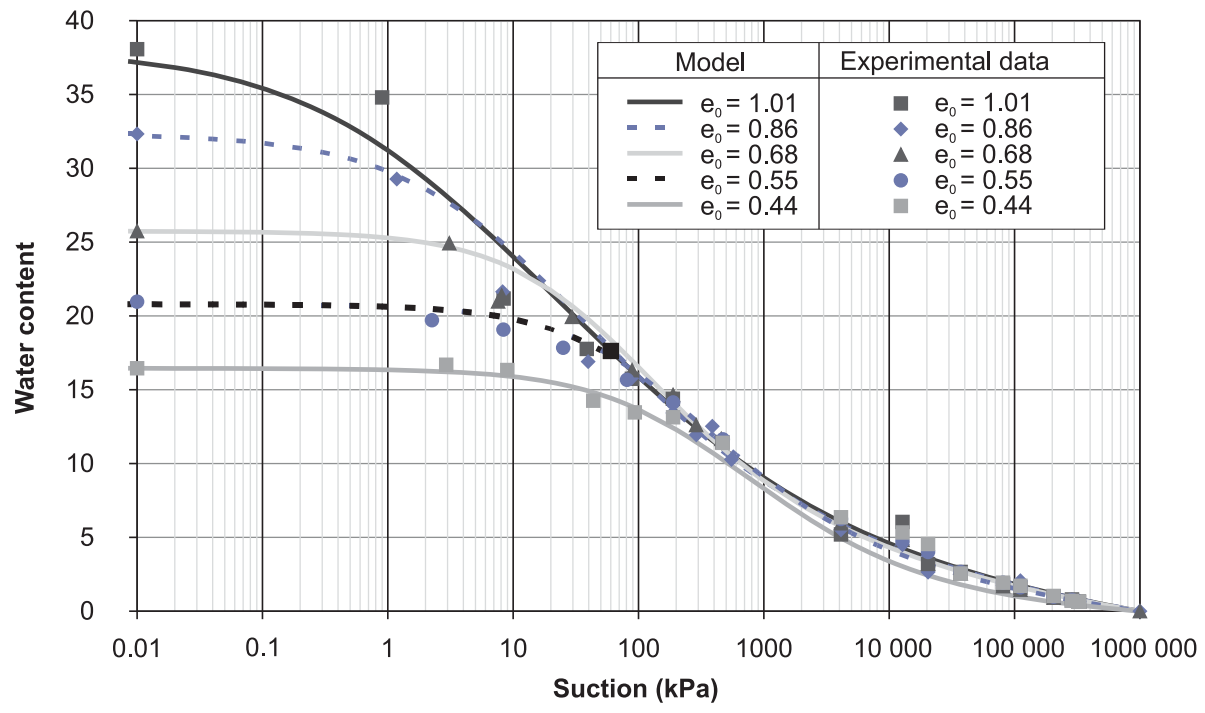

Fig. 5. Void ratio variations with the initial void ratio for different values of suction. $\alpha$, proportionality coefficient.

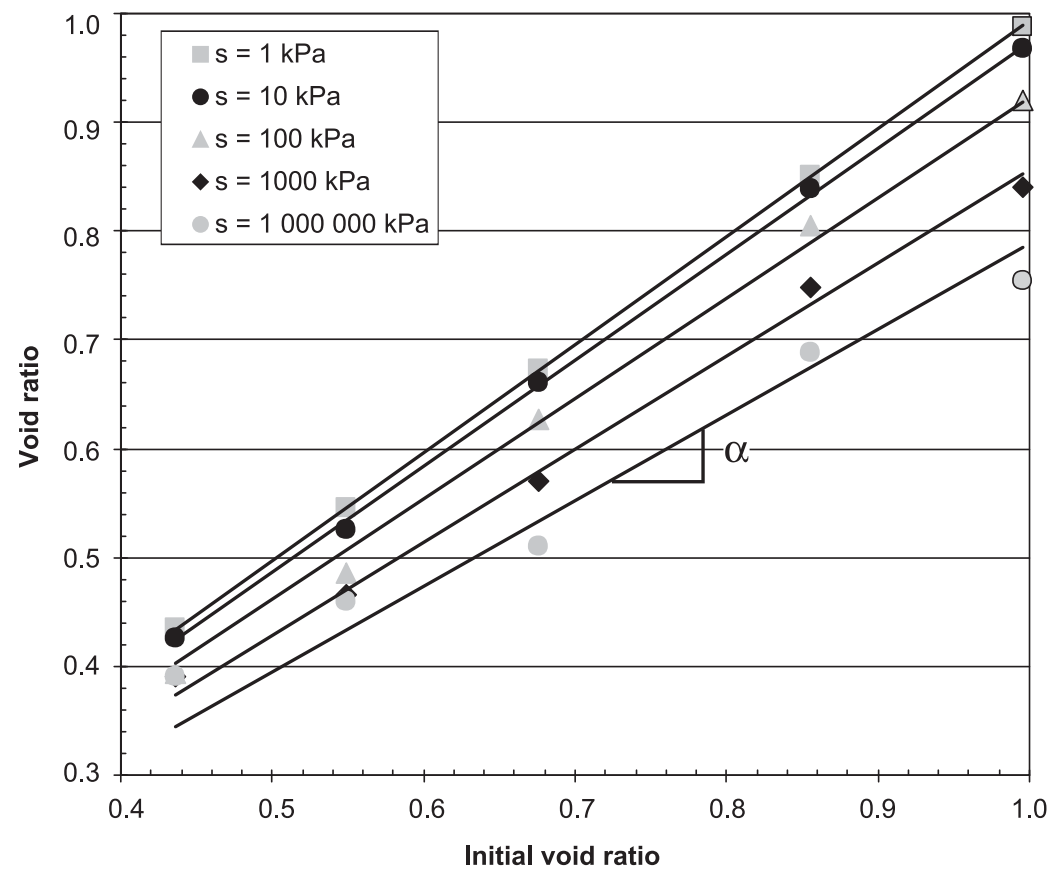

Fig. 6. Evolution of slope $\alpha$ with suction.

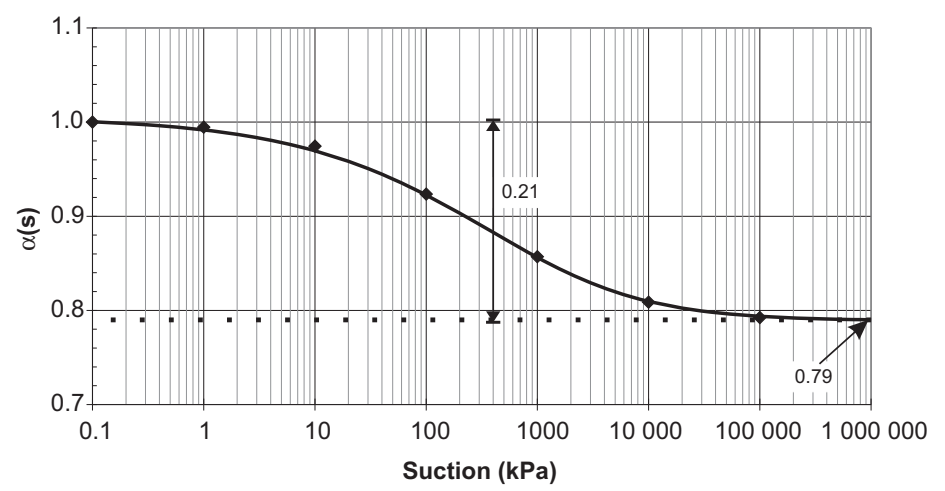


Fig. 7. Predicted and experimental data points of the main drying path projected on the plane $w=$ constant.

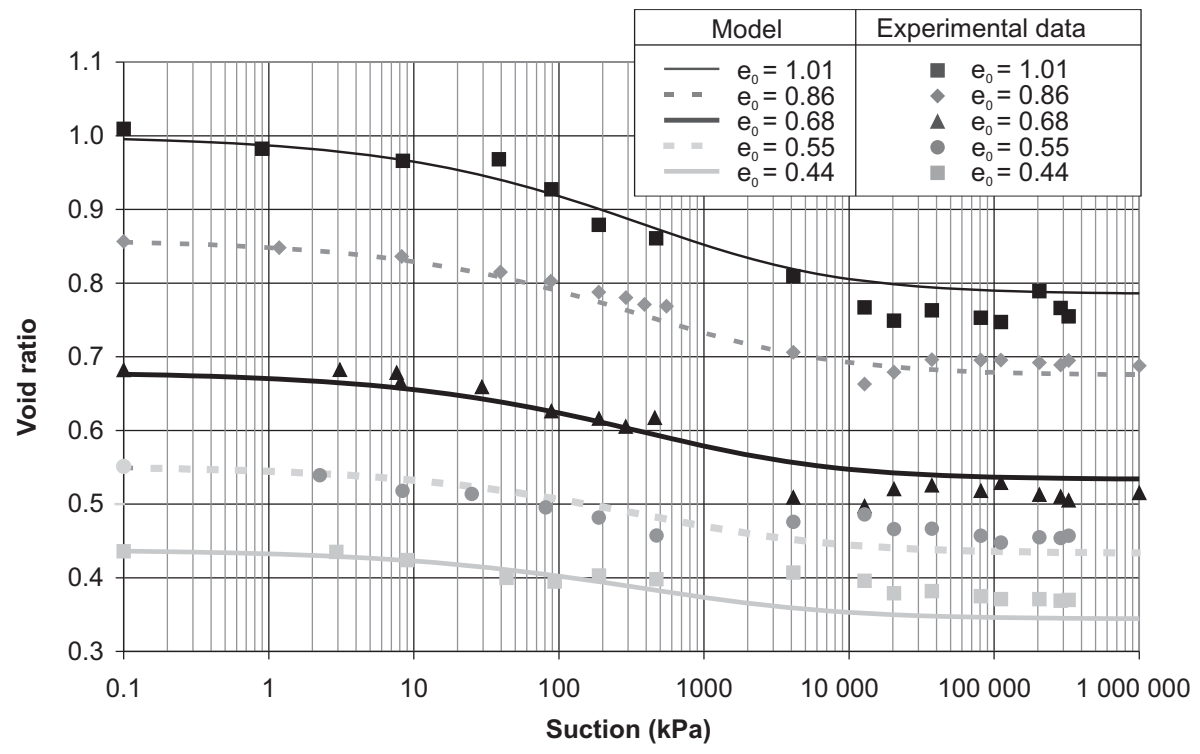

Fig. 8. Evolution of water content with the void ratio at given suction values.

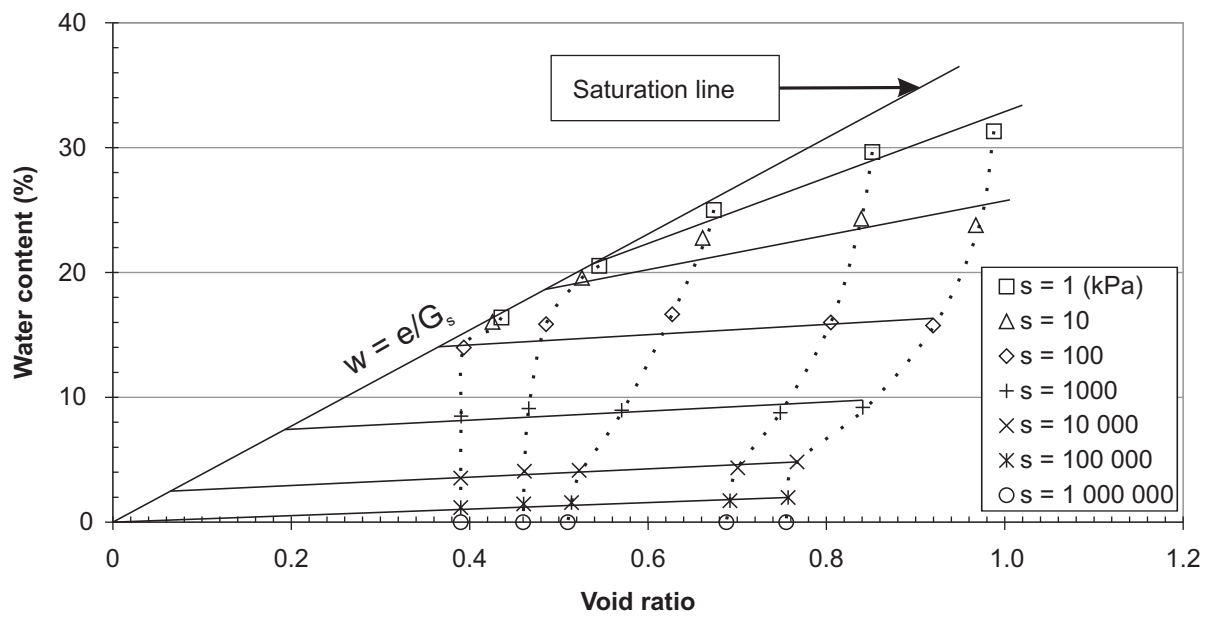

Figure 8 highlights the point that $a$ and $w_{\text {int }}$ decline with the increase in suction. Table 3 gives the values of these parameters for the nine suctions used. To plot these values in logarithmic scale, it is assumed that the saturation line corresponds to the very low suction of $0.1 \mathrm{kPa}$.

Figures 9 and 10 show the variation of the parameters $a$ and $w_{\text {int }}$ with suction. For the states close to saturation, $a(s)$, the slope of the lines $w(e)$ is equal to the coefficient of the saturation line $1 / G_{\mathrm{s}} \approx 1 / 2.65 \approx 0.377$. For higher suctions, this slope decreases very quickly. From $1000 \mathrm{kPa}$, slight nonmonotonous variations are observed, but they will not be taken into account in the model.

At low suctions, the intercept water content, $w_{\text {int }}$, remains constant and equal to 0.198. In the graph of Fig. 8, this means that all lines converge to the same point. Above a suction of $\simeq 10 \mathrm{kPa}, w_{\text {int }}(s)$ decreases.

The curves obtained for the two parameters as a function of suction have the same shape as the water retention curves. At low suctions, the evolution is slow; whereas, at
Table 3. Values of the parameters $a$ and $w_{\text {int }}$ for different suction values.

\begin{tabular}{lll}
\hline Suction, $s(\mathrm{kPa})$ & $a$ & $w_{\text {int }}(\%)$ \\
\hline 0.01 (saturation) & 0.3774 & - \\
0.1 & 0.377 & 19.8 \\
1 & 0.274 & 19.8 \\
10 & 0.141 & 18.6 \\
100 & 0.024 & 15.1 \\
1000 & 0.008 & 8.6 \\
10000 & 0.027 & 2.8 \\
100000 & 0.019 & 0.6 \\
1000000 & 0.000 & 0.0 \\
\hline
\end{tabular}

intermediate suctions, it is fast and it again becomes slow or equal to zero at still higher suctions. Equation [8] is used to capture these variations. Table 4 summarizes the values of the parameters of these two functions. The parameter $\varphi$, 
Fig. 9. Evolution of the slope $a(s)$ with suction.

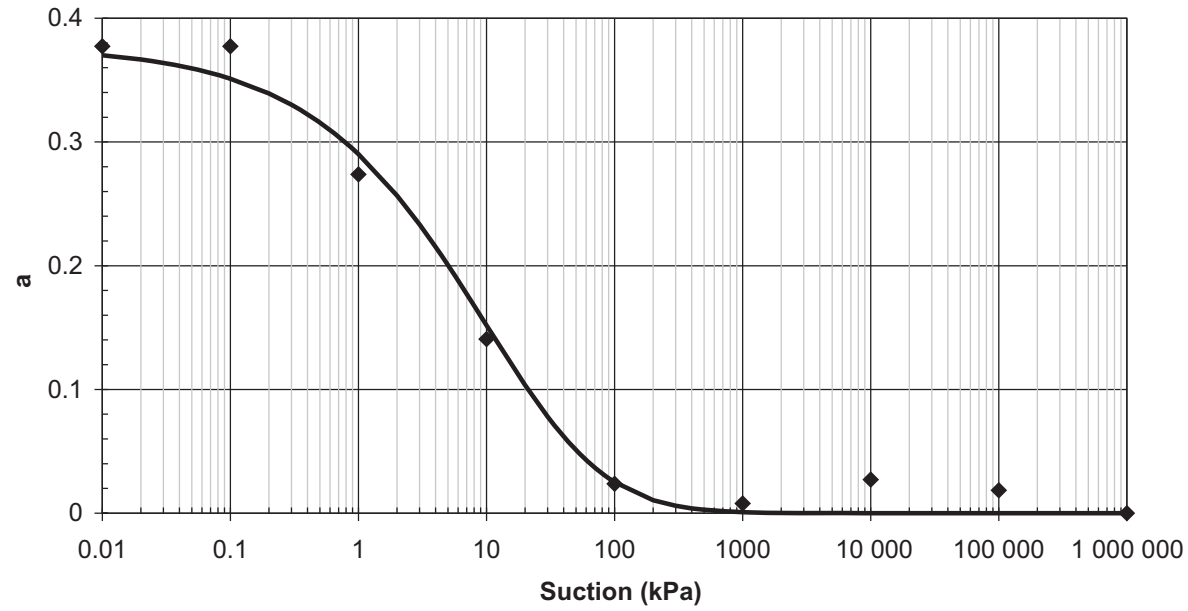

Fig. 10. Evolution of the intercept water content $w_{\text {int }}(s)$ with suction.

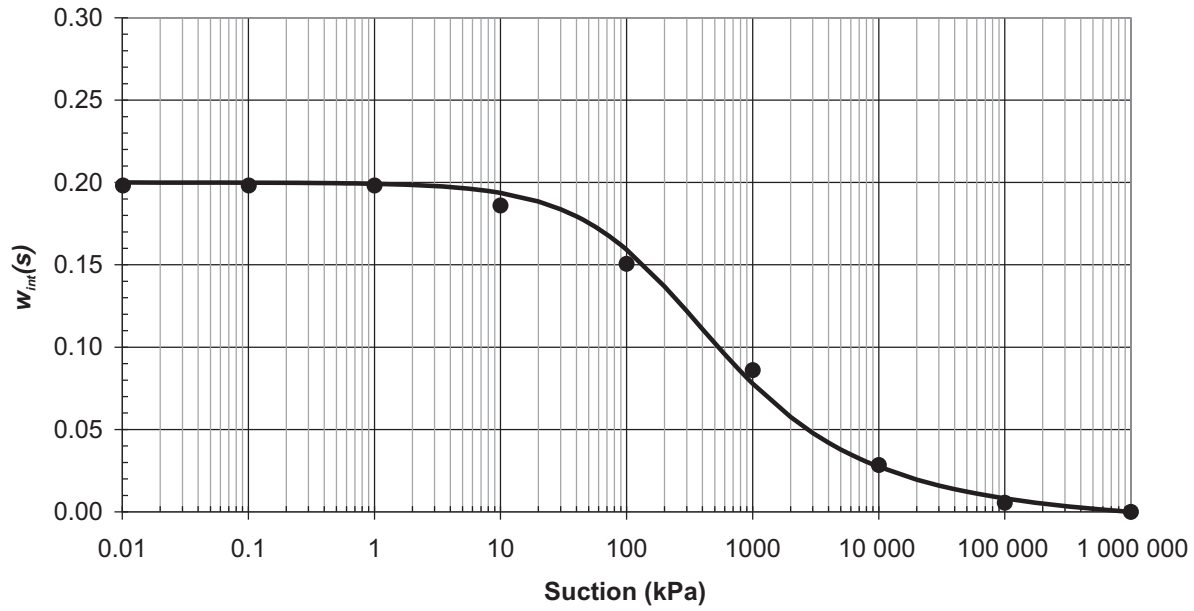

Table 4. Parameters of the fitting functions of a $(s)$ and $w_{\text {int }}(s)$.

\begin{tabular}{|c|c|c|c|c|c|c|c|}
\hline \multirow[b]{2}{*}{$\begin{array}{l}\text { Fitting } \\
\text { function }\end{array}$} & \multicolumn{7}{|l|}{ Parameters } \\
\hline & Equivalent $w_{\text {sat }}$ & $\varphi$ & $s_{\mathrm{p}}$ & $s_{\mathrm{r}}$ & $s_{\mathrm{i}}$ & $n$ & $m$ \\
\hline$a(s)$ & $1 / G_{\mathrm{s}} \approx 0.3774$ & -0.035 & 200 & 1000 & 80 & 0.57 & 9.00 \\
\hline$w_{\text {int }}(s)$ & 0.198 & -0.035 & 10000 & 2000 & 180 & 0.92 & 1.25 \\
\hline
\end{tabular}

which is the slope of the linear part at high variations, is the same for both functions.

From the expressions of $a(s)$ and $w_{\text {int }}(s)$ in the eq. [21], we get the equation of SWRS for the clayey silty sand. Figure 11 shows this surface. The SWRS can be split into the following three zones:

- Saturation - The suction is not equal to zero, but the pores of the soil are too small to let the suction loading begin to desaturate the medium. The air-entry value increases when the void ratio decreases.
- Void ratio dependence - This zone corresponds to the suctions below $\simeq 100 \mathrm{kPa}$ and void ratios above 0.4 .

- Void ratio independence - This zone corresponds to suctions above $100 \mathrm{kPa}$.

Figures $12 a$ and $12 b$ display, respectively, the SWRS of the clayey silty sand compared with the main drying paths and the SWRS in terms of degree of saturation. In Fig. 12a, one can note that the water retention curves corresponding to the higher values of initial void ratio do not cross the saturated zone, which means that the water content decreases 
Fig. 11. Soil-water retention surface of the clayey silty sand.

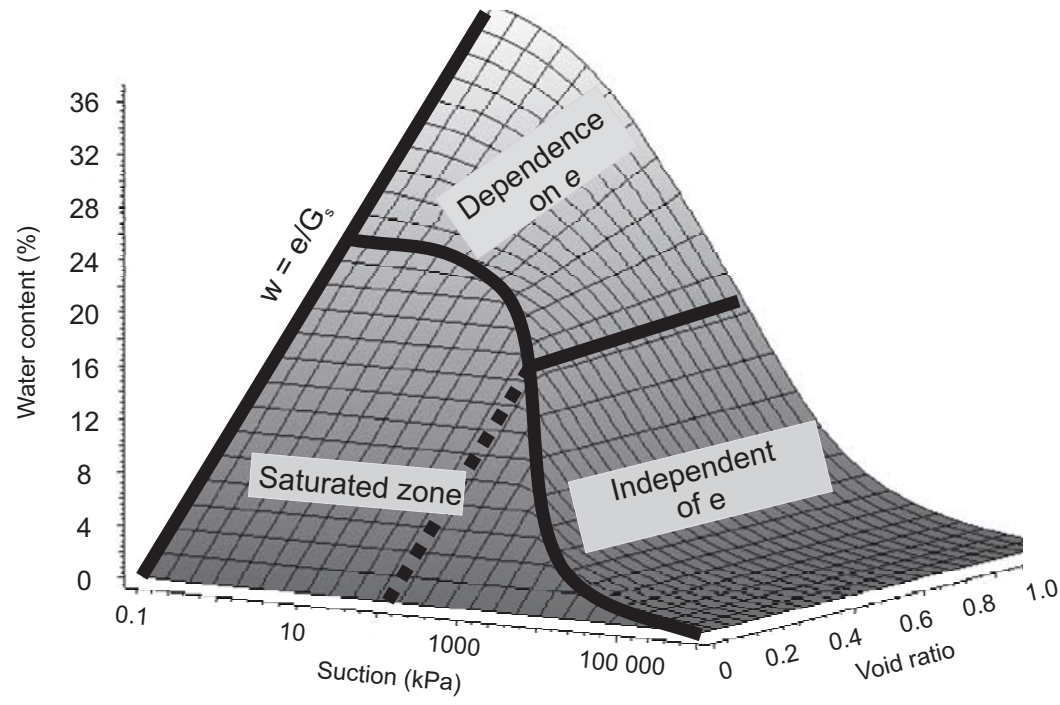

Fig. 12. (a) SWRS compared with the main drying paths and (b) SWRS in terms of degree of saturation.
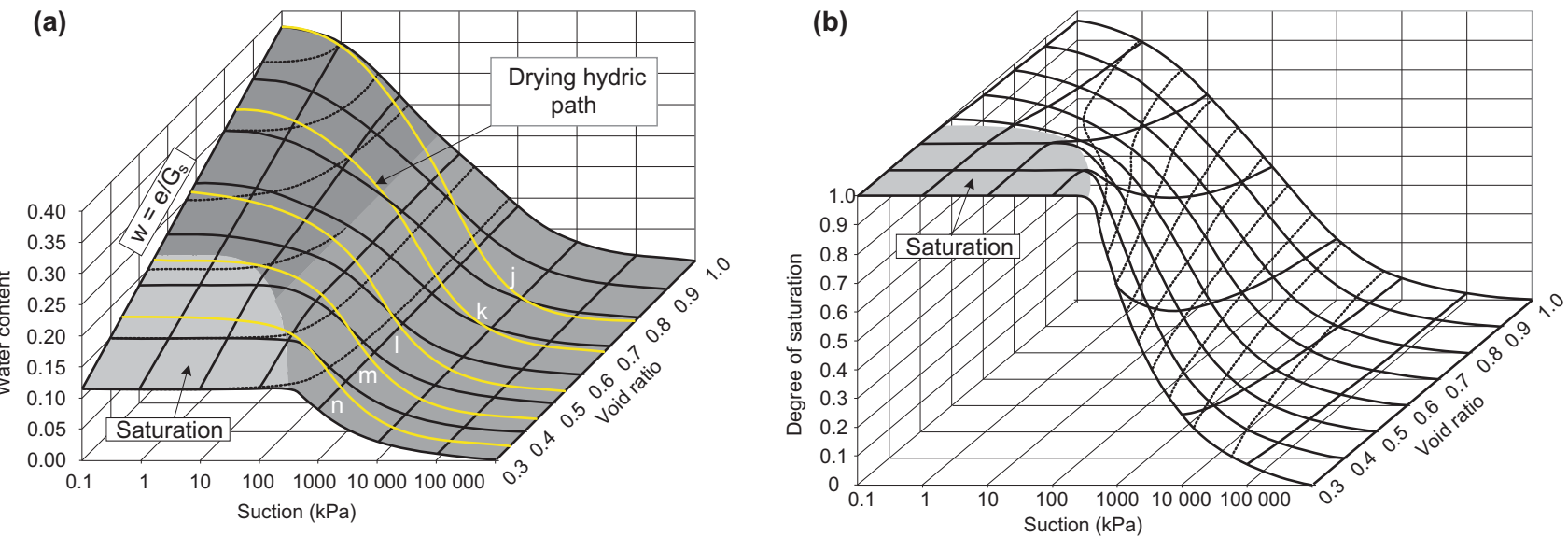

Fig. 13. Evolution of water content with suction for different constant values of the void ratio.

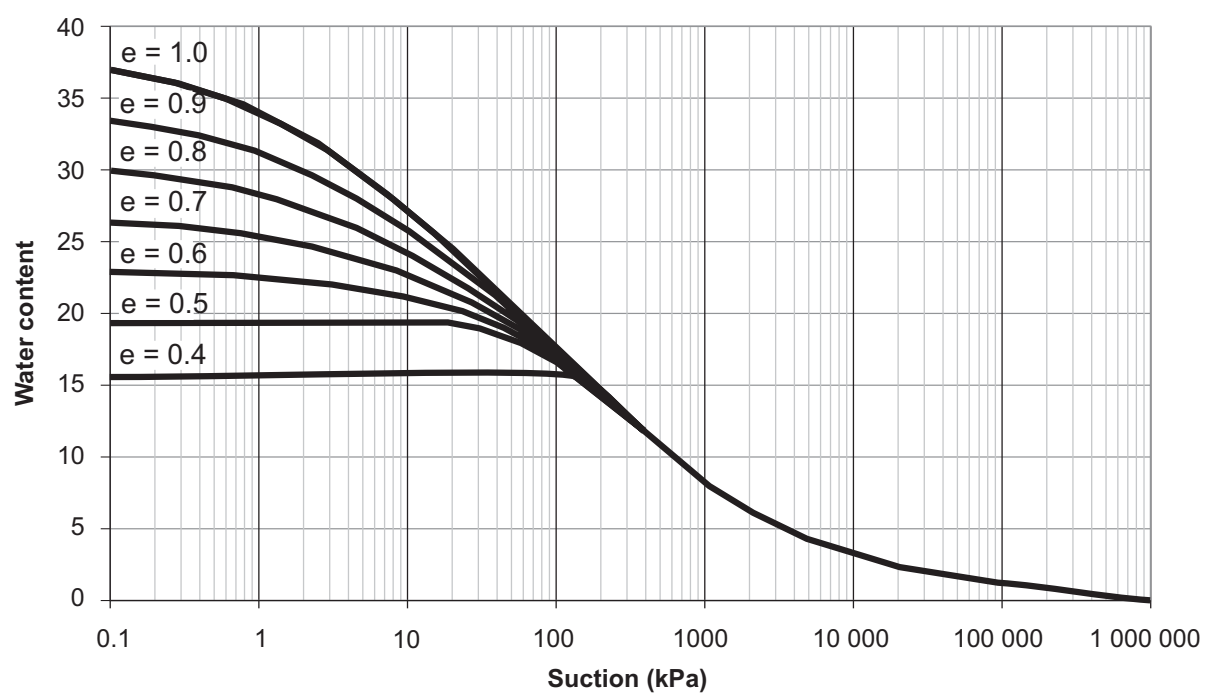


Fig. 14. $F_{w}$ evolution with respect to suction for different constant void ratios.

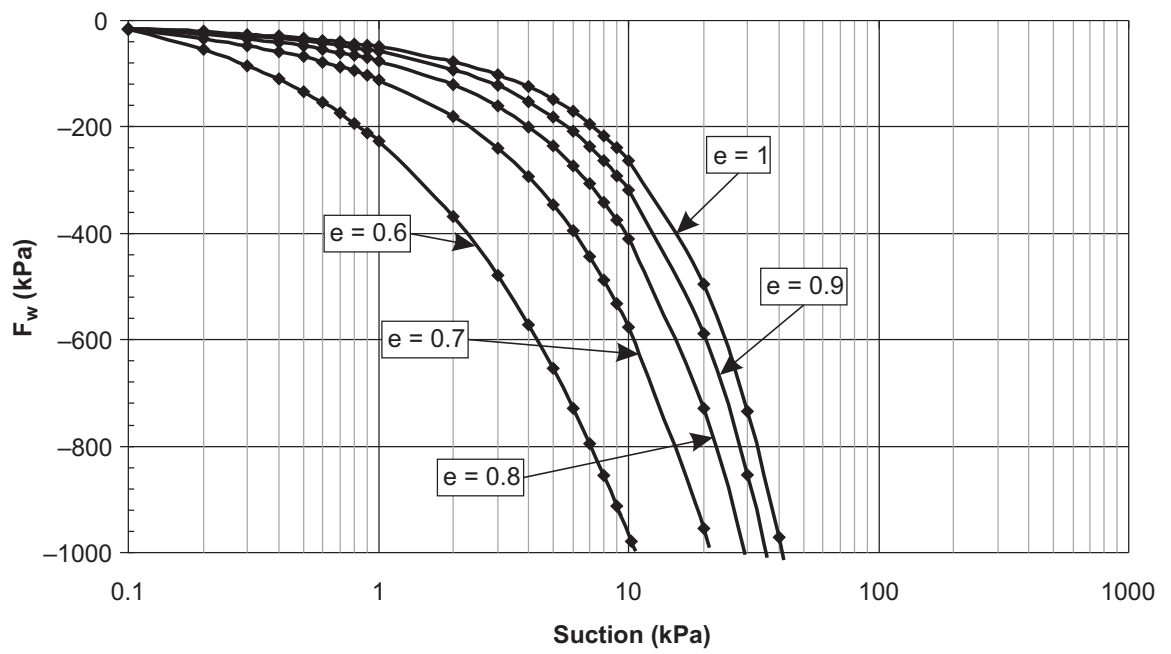

even for low suction. The graph highlights the variation of the void ratio along the main drying paths. When the SWRS is plotted in terms of degree of saturation, the saturation line is horizontal and the saturated zone is a plane where $S_{\mathrm{r}}$ keeps the value 1 even if the suction is not null. In this space, the effect of the density on the degree of saturation suction relation is not negligible even for the most drying states.

\section{Analysis of SWRS}

As an analytical framework for the study of SWRS, we propose the following formulation of a general evolution law expressing the variations of suction with respect to water content and void ratio:

$$
\mathrm{d} s=\left(\frac{\partial s}{\partial w}\right)_{e} \mathrm{~d} w+\left(\frac{\partial s}{\partial e}\right)_{w} \mathrm{~d} e
$$

The partial derivatives appearing in this equation are state functions

$$
F_{w}=\left(\frac{\partial s}{\partial w}\right)_{e}
$$

The function $F_{w}$ is associated with suction increment due to water content increment at constant void ratio. For an undeformable medium, this term is the negative slope of the water retention curve.

$$
\text { [24] } \quad F_{e}=\left(\frac{\partial s}{\partial e}\right)_{w}
$$

The function $F_{e}$ is associated with suction increment due to the increment of void ratio at constant water content.

Equation [22] underlines the fact that a function $f(s, w, e)=0$ linking the variations of suction, water content, and void ratio exists. The system of equations in eq. [21] defines this function $(f(s, w, e)=w-w(s, e)=0)$.
Fig. 15. Evolution of void ratio with suction for different constant values of water content.

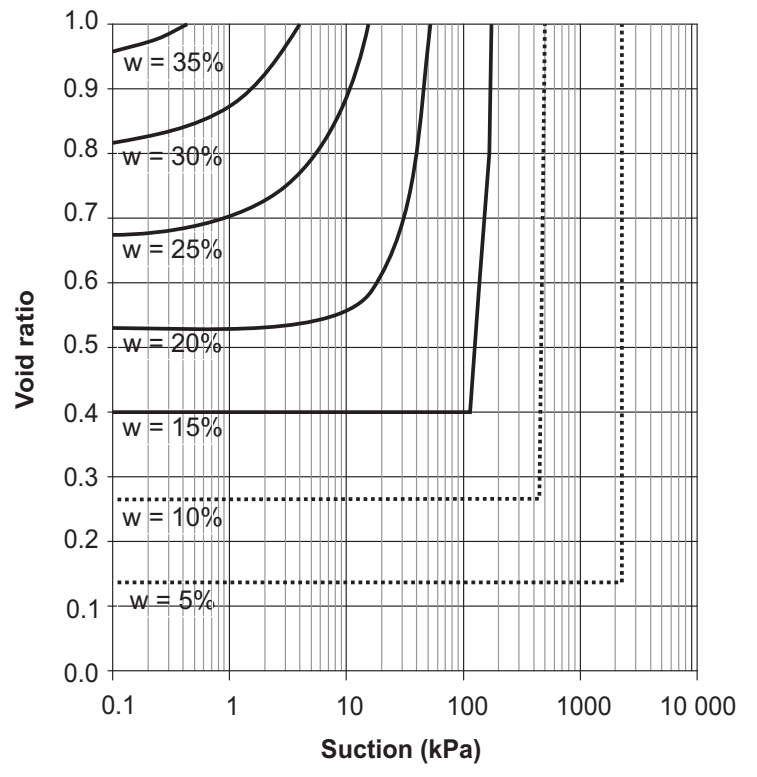

At a constant void ratio, eq. [22] is reduced to [25] $\mathrm{d} s=F_{w} \mathrm{~d} w$

Figure 13 presents the water retention curves of the clayey silty sand for constant values of void ratio. These curves are determined by means of the function $f$.

At high void ratios, the desaturation of the medium appears from the low suction values. For this range of void ratios it is clear that when the void ratio decreases, the airentry value grows. For the plot corresponding to $e=0.4$, 
Fig. 16. Evolution of $F_{e}$ with suction for different constant values of water content.

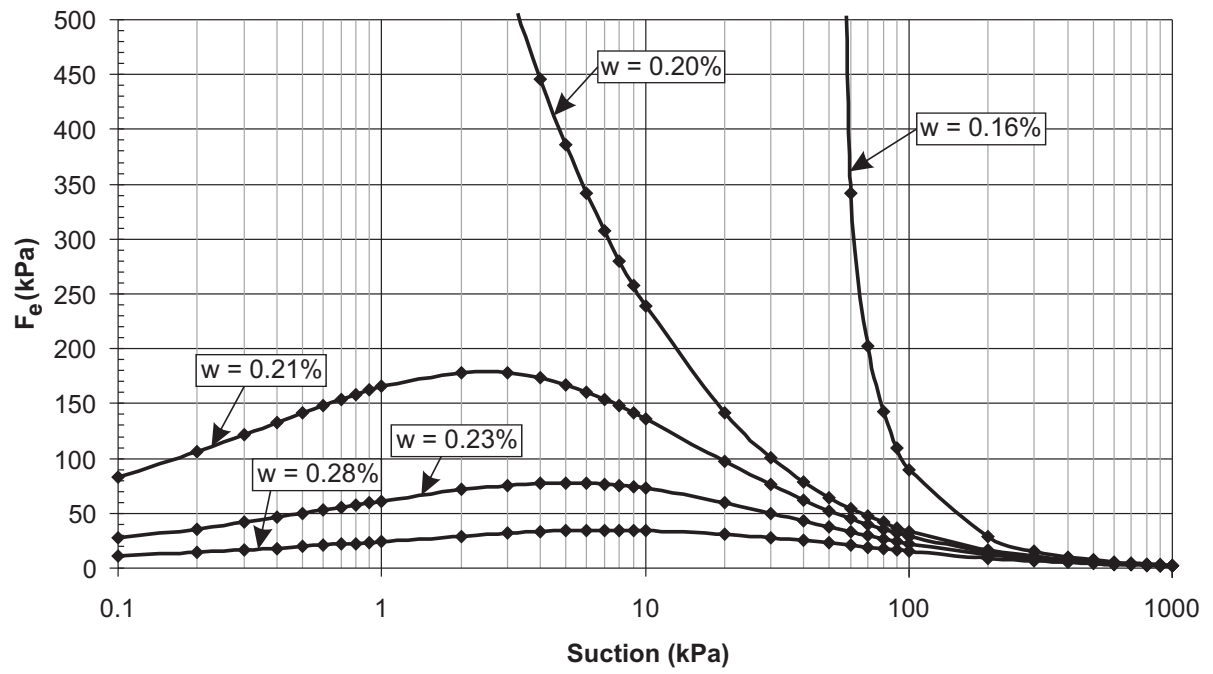

the systemin eq. [21] infers a steep transition from saturated to unsaturated states. It manifests itself graphically by a marked change in the slope.

$$
F_{w}(w, s, e)=\frac{1}{\frac{\partial a(s)}{\partial s}\left[e-w_{\text {int }}(s) G_{\mathrm{s}}\right]+\frac{\partial w_{\text {int }}(s)}{\partial s}\left[1-a(s) G_{\mathrm{s}}\right]}
$$

Figure 14 shows the evolution of $F_{w}$ with the suction for different values of the void ratio. $F_{w}$ is negative for the whole range of suction values. It is equal to 0 for a zero suction but it cannot be plotted in logarithmic scale.

At constant water content, eq. [22] is reduced to

$$
\text { [27] } \mathrm{d} s=F_{e} \mathrm{~d} e
$$

The function $F_{e}$ is the negative slope of the function $e=$ $e(s, w=$ consant $)$. Figure 15 shows the curves $e=e(s, w=$ constant) for different values of water contents determined by means of the function $f$. The general behaviour described by this graph is that, for a constant water content, an increase of the suction induces an increase of the void ratio. One can note that the opposite behaviour is observed in drained tests $(w \neq$ constant). With this void ratio evolution, the soil reduces its water retention capability and reaches a state compatible with the values of the imposed suction and water content. The higher the suction, the lower the density has to be. From a certain value of suction, it becomes impossible for the soil to reach a compatible state and consequently, the evolution of the void ratio with regards to the suction becomes assymptotic. As in Fig. 13, some curves exhibit marked changes in the slope, which are induced by the system in eq. [21]. These curves corresponding to water contents of $5 \%$ and $10 \%$ show the capability of the model to describe extreme states but do not have a real physical meaning.

The function $f$ allows one to obtain the following explicit form of the function $F_{e}$ :
The function $f$ leads to an explicit form of the function $F_{w}$

$$
F_{e}(w, s, e)=\frac{-a(s)}{\frac{\partial a(s)}{\partial s}\left[\frac{w}{a(s)}-\frac{w_{\text {int }}(s)}{a(s)}\right]+\frac{\partial w_{\mathrm{int}}(s)}{\partial s}\left[1-a(s) G_{\mathrm{s}}\right]}
$$

Figure 16 gives the evolution of $F_{e}$ with suction for different values of water content. $F_{e}$ is not a motonic function. As already mentionned for Fig. 15, only the plots corresponding to high enough water content values have a real physical meaning. Therefore, only the curves corresponding to values above $16 \%$ are plotted.

At constant suction, eq. [22] is reduced to

$$
\text { [29] } F_{w} \mathrm{~d} w+F_{e} \mathrm{~d} e=0
$$

Hence,

$$
\frac{\mathrm{d} w}{\mathrm{~d} e}=-\frac{F_{e}}{F_{w}}
$$

From eq. [15], it can be deduced that the derivative of water content with respect to void ratio is equal to the function $a(s)$. The same result is obtained when expanding the ratio $-F_{e} / F_{w}$ with eqs. [26] and [28]. The water content variations with respect to void ratio for different constant values of the suction were presented in Fig. 8.

\section{Conclusion}

In the field of hydromechanical characterization, only few results exist. The reported results provide only partial and simplified representations through the water retention curve. Retention behaviour defined in this way does not account for the phenomena inducing hydromechanical couplings. To 
fill this gap, a detailed study is presented in this paper, making it possible to define a more general concept of soil-water retention surface (SWRS) and to give a representation of it on the basis of broad experimental data.

In the section titled "Basic elements of hydromechanical coupling," we described basic elements of hydromechanical couplings with respect to both theoretical and experimental aspects. The development of a more general tool than the water retention curve was motivated by the necessity for characterizating the retention behaviour of soils.

An experimental method to determine the SWRS was then presented and applied to a clayey silty sand. The determination of the surface was based on the measurement of the triplets $(e, s, w)$ along the main drying paths. These paths were established for five different initial states characterized by their void ratio and water content at saturation. The experimental data allowed us to define the parametric equations of the main drying paths, which express both water content and void ratio as two functions of suction and initial void ratio.

A SWRS model of the clayey silty sand was then etablished in the space void ratio - suction - water content. This surface presents all possible states of the soil inside the investigated range of the three variables. Three zones could be clearly differentiated on the SWRS: saturation, void ratio dependence, and void ratio independence. Most of the results obtained in this framework can be generalized and the SWRS appears as a powerful tool for the characterization of the retention behaviour of deformable soils taking into account hydromechanical couplings. Finally, by means of an analytical framework based on the differential of the suction with regard to water content and void ratio, the SWRS was used to study the relations between water content and suction at constant void ratio and between void ratio and suction at constant water content.

\section{References}

Al-Mukhtar, M., Qi, Y., Alcover, J.F., and Bergaya, F. 1999. Oedometric and water-retention behavior of highly compacted unsaturated smectites. Canadian Geotechnical Journal, 36(4): 675-684. doi:10.1139/cgj-36-4-675.

ASTM. 2006. Standard practice for classification of soils for engineering purposes (Unified Soil Classification System). ASTM standard D2487. American Society for Testing and Materials, West Conshohocken, $\mathrm{Pa}$.

Biarez, J., Fleureau, J.M., Zerhouni, M.I., and Soepandji, B.S. 1988. Variations de volume des sols argileux lors de cycles de drainage-humidification. Revue Française de Géotechnique, 41: 63-71.

Biot, M.A. 1972. Theory of finite deformations of porous solids. Indiana University Mathematics Journal, 21(7): 597-620. doi:10.1512/iumj.1972.21.21048.

Brooks, R.H., and Corey, A.T. 1964. Hydraulic properties of porous medium. Civil Engineering Department, Colorado State University, Fort Collins, Colo. Hydrology Paper No. 3.

Coussy, O. 1995. Mechanics of porous media. John Wiley and Sons, Inc., New York.

Delage, J., and Graham, J. 1995. The mechanical behaviour of unsaturated soils. In Proceedings of the 1st International Conference on Unsaturated soils, Paris, 6-8 September 1995. Edited by E.E. Alonso and P. Delage. Balkema, Rotterdam, the Netherlands. Vol. 3, pp. 1223-1256.
Delage, P., Howat, M.D., and Cui, Y.J. 1998. The relationship between suction and swelling properties in a heavily compacted unsaturated clay. Engineering Geology, 50(1-2): 31-48. doi:10. 1016/S0013-7952(97)00083-5.

Devillers, P., El Youssoufi, M.S., and Saix, C. 2008. A framework for the Construction of state surfaces of unsaturated soils in the elastic domain. Water Resources Research, 44: W00C08. doi:10. 1029/2007WR006573.

Ferber, V., Auriol, J.-C., Cui, Y.-J., and Magnan, J.-P. 2008. Wetting-induced volume changes in compacted silty clays and highplasticity soils. Canadian Geotechnical Journal, 45(2): 252-265. doi:10.1139/T07-081.

Fleureau, J.-M., Verbrugge, J.-C., Huergo, P.J., Gomes Correia, A., and Kheirbek-Saoud, S. 2002. Aspects of the behaviour of compacted clayey soils on drying and wetting paths. Canadian Geotechnical Journal, 39(6): 1341-1357. doi:10.1139/t02-100.

Fredlund, D.G. 1979. Second Canadian Geotechnical Colloquium: Appropriate concepts and technology for unsaturated soils. Canadian Geotechnical Journal, 16(1): 121-139. doi:10.1139/t79-011.

Fredlund, D.G., and Morgenstern, N.R. 1976. Constituve relations for volume change in unsaturated soils. Canadian Geotechnical Journal, 13(3): 261-276. doi:10.1139/t76-029.

Fredlund, D.G., and Pham, H.Q. 2007. Independent roles of the stress state variables on volume-mass constitutive relations. In Proceedings of the 2nd International Conference on Mechanics of Unsaturated Soils, Weimar, Germany, 7-9 March 2007. Springer Proceedings in Physics, 112. Edited by T. Schanz. Springer-Verlag, Berlin. pp. 1223-1256.

Fredlund, D.G., and Xing, A. 1994. Equations for the soil-water characteristic curve. Canadian Geotechnical Journal, 31(4): 521-532. doi:10.1139/t94-061.

Gardner, W.R. 1958. Some steady-state solutions of the unsaturated moisture flow equation with application to evaporation from a water table. Soil Science, 85(4): 228-232. doi:10.1097/ 00010694-195804000-00006.

Head, K.H. 1980. Manual of soil laboratory testing: soil classification and compaction tests. Pentech Press, London.

Imbert, C., Olchitzky, E., Lassabatère, T., Dangla, P., and Courtois, A. 2005. Evaluation of a thermal criterion for an engineered barrier system. Engineering Geology, 81(3): 269-283. doi:10.1016/ j.enggeo.2005.06.019.

Karube, D., and Kawaï, K. 2001. The role of pore water in the mechanical behavior of unsaturated soils. Geotechnical and Geological Engineering, 19(3/4): 211-241. doi:10.1023/ A: 1013188200053 .

Kawaï, K., Karube, D., and Kato, S. 2000. The model of water retention curve considering effect of void ratio. In Unsaturated Soil for Asia: Proceedings of the Asian Conference on Unsaturated Soils, UNSAT-ASIA 2000, Singapore, 18-19 May 2000. Edited by H. Rahardjo, D.G. Toll, and E.C. Leong. Balkema, Rotterdam, the Netherlands. pp. 329-334.

Kosugi, K. 1994. The parameter lognormal distribution model for soil water retention. Water Resources Research, 30(4): 891-901. doi:10.1029/93WR02931

Li, X.S. 2005. Modelling of hysteresis response for arbitrary wetting/drying paths. Computers and Geotechnics, 32: 133-137.

Miller, C.J., Yesiller, N., Yaldo, K., and Merayyan, S. 2002. Impact of soil type and compaction conditions on soil water characteristic. Journal of Geotechnical and Geoenvironmental Engineering, 128(9): 733-742. doi:10.1061/(ASCE)10900241(2002)128:9(733).

Nuth, M., and Laloui, L. 2008. Advances in modelling hysteretic water retention curve in deformable soils. Computers and Geotechnics, 35(6): 835-844. doi:10.1016/j.compgeo.2008.08.001. 
Olchitsky, E. 2002. Couplage hydromécanique et perméabilité d'une argile gonflante non saturée sous sollicitations hydriques et thermiques. Ph.D. thesis, École Nationale des Ponts et Chaussées, Paris.

Péron, H., Hueckel, T., and Laloui, L. 2007. An improved volume measurement for determining soil water retention curves. Geotechnical Testing Journal, 30: 1-8.

Pham, H., Fredlund, D., and Barbour, S. 2005. A study of hysteresis models for soil-water characteristic curves. Canadian Geotechnical Journal, 42(6): 1548-1568. doi:10.1139/t05-071.

Romero, E. 1999. Characterisation and thermo-hydro-mechanical behaviour of unsaturated boom clay: experimental study. Ph.D. thesis, Universitat Politechnica de Catalunya, Barcelona, Spain.

Romero, E., and Vaunat, J. 2000. Retentions curves of deformable clays. In proceedings of Experimental evidence and theoretical approaches in unsaturated soils. Balkema.

Romero, E., Gens, A., and Lloret, A. 2001. Temperature effect on the hydraulic behaviour of an unsaturated clay. Geotechnical and Geological Engineering, 19(3/4): 311-332. doi:10.1023/ A:1013133809333.

Saix, C. 1991. Consolidation thermique par chaleur d'un sol non saturé. Canadian Geotechnical Journal, 28(1): 42-50. doi:10. 1139/t91-005.

Salager, S. 2007. Etude de la retention d'eau et de la consolidation des sols dans un cadre thermo-hydromécanique. Ph.D. thesis, Université Montpellier 2, Montpellier, France.

Salager, S., Jamin, F., El Youssoufi, M.S., and Saix, C. 2006. Influence de la température sur la courbe de rétention d'eau de milieux poreux. Comptes Rendus Mécanique, 334(6): 393-398. doi:10.1016/j.crme.2006.05.003.

Salager, S., El Youssoufi, M.S., and Saix, C. 2007. Experimental study of the water retention curve as a function of void ratio. In Computer Applications In Geotechnical Engineering: Proceedings of Sessions of GeoDenver, Denver, Colo., 18-21 February 2007. Geotechnical Special Publication 157. Edited by T.C. Siegel, R. Luna, T. Hueckel, and L. Laloui. American Society of Civil Engineers, Reston, Va. pp. 1-10.

Salager, S., El Youssoufi, M.S., and Saix, C. 2008. Temperature effect on hydric behaviour for unsaturated deformable soils. In
Unsaturated Soils: Advances in Geo-Engineering, Proceedings of the First European Conference on Unsaturated Soils (E-UNSAT), Durham, UK, 2-4 July 2008. D.G. Toll, C.E. Augarde, D. Gallipoli, and S.J. Wheeler. CRC Press/Balkema, Leiden, the Netherlands. pp. 683-688.

Sugii, T., Yamada, K., and Kondou, T. 2002. Relationship between soil-water characteristic curve and void ratio. In Proceedings of the 3rd International Conference on Unsaturated Soils, Recife, Brazil, 10-13 March 2002. Edited by J.F.T. Juco, T.M.P. De Campas, and F.A.M. Marinho. Swets and Zeitlinger, Rotterdam, the Netherlands. Vol. 1, pp. 209-214.

Sun, D.A., Sheng, D.C., and Xu, Y.F. 2007. Collapse behaviour of unsaturated compacted soils with different initial densities. Canadian Geotechnical Journal, 44(6): 673-686. doi:10.1139/T07-023.

Tang, A.M. 2005. Effet de la température sur le comportement des barrières de confinement. Ph.D. thesis, École Nationale des Ponts et Chaussées, Paris.

Tarantino, A., and Tombolato, S. 2005. Coupling of hydraulic and mechanical behaviour in unsaturated compacted clay. Géotechnique, 55(4): 307-317. doi: 10.1680/geot.2005.55.4.307.

Van Genuchten, M.T. 1980. A closed-form equation for predicting the hydraulic conductivity of unsaturated soils. Soil Science Society of America Journal, 44: 892-898.

Vanapalli, S.K., Fredlund, D.G., and Pufahl, D.E. 1999. The influence of soil structure and stress history on the soil-water characteristics of a compacted till. Géotechnique, 49(2): 143-159. doi:10.1680/geot.1999.49.2.143.

Verbrugge, J.C., and Fleureau, J.M. 2002. Bases expérimentales du comportement des sols non saturés. In Mécanique des sols non saturés. Edited by O. Coussy and J.M. Fleureau. Hermès science, Paris. pp. 69-112.

Watabe, Y., Leroueil, S., and Le Bihan, J.P. 2000. Influence of compaction conditions on pore-size distribution and saturated hydraulic conductivity of a glacial till. Canadian Geotechnical Journal, 37(6): 1184-1194. doi:10.1139/cgj-37-6-1184.

Zhou, J., and Yu, J.L. 2004. Influences affecting the soil-water characteristic curve. Journal of Zhejiang University Sciences, 6(8): 797-804. 